Chemistry surpass in numbers, they also outdo in individual productiveness, the workers in Physics. But since the institution of physical laboratories is nevertheless spreading, the very novelty of their existence makes the publication of books like that of Prof. Kohlrausch, proceeding from older establishments, a real boon to those called upon to superintend or take a share in the direction of the practical work of new ones; and it is only to be hoped that from other places of renown also, both in England and abroad, similar publications may also soon proceed.

C. K. AKIN

GALLOWAY'S QUALITATIVE ANALYSIS

Manual of Qualitative Analysis. By Robert Galloway, F.C.S. Fifth edition, xxi. and $4 \mathrm{I} 5$ pp. (London: John Churchill and Sons.)

$\mathrm{O}^{\mathrm{s}}$ $F$ the various manuals of Qualitative Analysis now in use, none is more deservedly popular than the work of Professor Galloway. Much of this success is doubtless due to the painstaking care with which the author has sought in successive editions to reduce the operations of Qualitative Analysis to a more methodical and systematic process. The present edition is in great part rewritten, and much new and original matter has been incorporated. More systematic methods for separating the alkaloids are given, together with many additional reactions for their individual discrimination. The processes for detecting the poisonous metals in presence of organic matters are also much improved. A description of Bunsen's neat and expeditious flame reactions is likewise a new feature in the book. The delicacy and certainty of these reactions ought undoubtedly to lead to their more general adoption in our laboratories; even if their application is found to be limited, the lesson in neatness and dexterity in working to be acquired in their performance would prove invaluable to the student.

One of the characteristics of this book is its thoroughness, and the very example of this quality will not be lost upon the beginner. As an illustration of what we mean, we give the following extract from the introductory remarks on the province and scope of qualitative analysis:

The analyst, by means of re-agents, interrogates the substance to be analysed as to what are its component parts; the reaction are the language in which the answer is returned. The student has therefore to learn the mode of questioning the substance, and the Ianguage in which the answer will be conveyed; in other words, he has to leam, not only what general and special re-agents are to be employed, but the order in which they are to be applied, and also the reactions they produce with the bases and acidradicals, before he can attempt to search for these bodies in substances. No amount of reading or lecture-hearing will furnish the student with this knowledge; he can only obtain it by making the experiments himself of the different bases and acid-radicals with the re-agents, and " $h \in$ must alwoyys reflect, before the addition of the re-agent, for what purpose he applies it, and what are the phenomena he intends to produce." And the conditions indispensable for the production of correct and decisive reactions must be carefully observed, for a half-knowledge in all depart ments of science is of little worth, but in chemical analysis it is worse than useless.

There must always be diversity of opinion respecting the best method of teaching Qualitative Analysis, or indeed of teaching any branch of practical science; since so much depends upon the qualifications and conscientiousness of the teacher. In the Preface to the present edition of his book, Professor Galloway makes some very pertinent observations respecting the advantages which the method he adopts possesses over that employed by Fresenius and in the Giessen Outines. It is quite possible that by faithfully following the plan laid down by the German professor, the student may succeed in correctly determining a larger proportion of the mixtures given to him for analysis, and yet the amount of actual benefit whigh may accrue to him may be far less than if he were more frequently unsuccessful by working under a system which left more to his individual judgment and intelligence. We believe that the method of Fresenius, as an educational agent, is radically bad; its tendency is to make the learner degenerate into a mere analytical machine. Such a system (to employ the phraseology of Mr. Galloway), of simply telling this and showing that, may be most pernicious in its consequences. The chief object in teaching chemistry is thus too frequently missed; science so studied renders the student utterly incapable of correctly reasoning upon the knowledge he acquires, for merely to create a number of proficient analysts is not the primary end of the introduction of qualitative analysis into the curriculum of our schools and colleges. A perfect system, then, is that which, whilst employing the most satisfactory and expeditious analytical methods, yet allows sufficient latitude for the student to exercise and strengthen the powers of his originality, reason, and intelligence. Such a system Professor Galloway has attempted to frame, and we have no hesitation in asserting that in the hands of a conscientious student his book will lead to the result which he desires to obtain.

T. E. THORPE

\section{WORKS IN NATURAL HISTORY}

Works in Natural History, ENc. By the Rev. F. O. Morris, B.A.

THIS is, in several respects, a very remarkable pamph1 let. It shows us, to our great gratification, that the study of Natural History is, thanks to the labours of Mr. Morris, gradually finding its way into Royal Palaces and Baronial Halls, for we learn that Her Most Gracious Majesty the Queen has accepted the dedication of his "History of British Birds;" that his Excellency the Right Honourable the Earl of Carlisle, K.G, \&c. \&c., influenced probably by Her Majesty's example, has extended his patronage in a similar manner to the "Natural History of the Nests and Eggs of British Birds;" that his "British Butterflies" and "British Moths" are under the genial and aristocratic guardianship of the Honourable Mrs. Musgrave and the Right Hon. Lady Muncaster ; that his "Anecdotes in Natural History," and "Records of Animal Sagacity and Character," are dedicated by permission to the Most Hon. the Marquis of Westminster, K.G. and the Hon. Anne Emma Caven dish; while His Grace the Archbishop of York stands sponsor to "The Difficulties of Darwinism." Surely even in the so-called Golden Age of English literature, no author could have had the good fortune to secure so many noble patrons.

Appended to the title of each of Mr. Morris's works are "Notices of the Press," and in this department the compiler of the pamphlet would, we think, have acted more wisely and more in accordance with the dignity of 